\title{
Semantic Shift in the Kenyan Prison Argot
}

\author{
Ogutu Peter Okoth ${ }^{1,}$, Oluoch Stephen ${ }^{2}$, Opande Nilson Isaac ${ }^{2}$ \\ ${ }^{1}$ Department of Kiswahili and Other African Languages, Maseno University, Maseno, Kenya \\ ${ }^{2}$ Department of Language, Literature and Linguistics, Kisii University, Kisii, Kenya
}

Email address:

Pitarion2@yahoo.com (O. P. Okoth), Yahuma1976@yahoo.com (O. Stephen), Opanilson@gmail.com (O. N. Isaac)

${ }^{*}$ Corresponding author

\section{To cite this article:}

Ogutu Peter Okoth, Oluoch Stephen, Opande Nilson Isaac. Semantic Shift in the Kenyan Prison Argot. Communication and Linguistics Studies. Vol. 5, No. 1, 2019, pp. 23-29. doi: 10.11648/j.cls.20190501.15

Received: March 29, 2019; Accepted: May 15, 2019; Published: June 13, 2019

\begin{abstract}
Prison argot is a language variety with great creativity manifested in its semantic richness. This variety of language has received the attention of many scholars in the western countries in different periods of time. Despite prison being a rich semantic vessel, prison lingo has not received the proper attention of linguists in Africa. The end result is that very few linguistic conclusions have been reached regarding this variety of language in Kenya. The main aim of this paper is to examine the semantic shift in the Kenyan prison argot based on the lexical pragmatic framework. The paper provides an overview of this subject matter by analyzing the various types of semantic shifts through definitions and example of the argot terms affected. The processes involved in the case of semantic change include lexical narrowing and lexical broadening with some of its varieties namely; metaphoric extensions and hyperbole. The study was carried out at Kibos and Kisumu maximum-security prisons in Kisumu County, Kenya. Forty respondents were selected to participate in the study. In lexical broadening, standard Swahili words were found to have been given additional meaning in the prison context. In lexical narrowing, the semantic meaning of some Swahili words were found to have been narrowed. The paper established that the inmates change the meaning of words in the prisons so as to hide secretes from the prisons officers.
\end{abstract}

Keywords: Semantic Shift, Semantic Change, Lexical Narrowing, Lexical Broadening, Metaphoric Extension, Hyperbole

\section{Introduction}

Prisoners behind the walls are not imprisoned by any rules regarding language, other than the fundamental properties of language as such [1]. The prisoners can, therefore, make changes in their language as they wish. They distort the meaning of words from standard languages, this is under the domain of semantic shift. Semantic shift has been one of the notions in the foreground of linguistic research. Looking at the dynamic nature of language, change is always pervading and ever-present [2].

Ullman (1977) explains that the idea of semantic change was introduced into linguistics by Sapir who observed that “...every word, every grammatical element...is slowly changing configuration molded by the invisible and impersonal drift that is the life of a language" [43]. Keith \& Shuttleworth (2000) confirm this by pointing out that language must change in order for it to remain alive [3].

A Semantic shift takes place when a word is used to express a meaning which it did not have previously [4]. Therefore, change of meaning concerns a shift of the relationship between words on the one hand and integral senses on the other hand [5].

Just like any other slang, the Kenyan prison argot contains words which have been formed by changing the meaning of words from the standard language. The prisoners use the words from the standard Swahili language or Standard English differently in order to fit into the context at hand. There are numerous reasons why prisoners give languages new meaning [1]. First, they have an inner desire to be different from others and therefore form their own language to express themselves. Secondly, to camouflage or hide their true intentions. Thirdly to make a distinct culture; fourthly, to encapsulate their own world view, and, fifthly to organize their reality so as to better understand, relate and react to it.

In Kenya, studies pertaining to semantic change in slang 
are rather limited. More limited is the research on the semantic shift in the prison lingo. Much of the researches in slang have majorly been done on language varieties found in the free world [6]. For example, Mugendi (2016) researched on the Morphology of the Gitamanya Argot of the Matatu Crew of Embu Town [7]. This research involved the argot used by the passenger service vehicle operators. Nyakundi (2010) on the other hand studied the Morpho-phonological Processes in Egesemba Argot Among Ekegusi-speaking Males of Western Kenya. All these studies analyzed argots used in the free society the society [8].

Ogutu, Opande \& Oluoch (2018) were the first scholars to carry out a linguistic study of the Kenyan prison argot. In their work they explain that this lingo is referred to as Kiswahili ya jela, a language full of tricks and lies. The paper analyzed the various features of the argot.

This neglect should not be surprising because access to prisons is limited or even impossible [1]. Ciechanowska \& Kleparski (2015) confirm this assertion by saying that data collection in prisons is problematic because the subculture of prison institutions is extremely difficult to penetrate since the prisoners carefully protect a lot of information [10].

Regardless of the challenges involving data collection in prisons, many scholars have attempted to give account for the prison culture, including its language [10]. The current study contributes to that research by analyzing the semantic changes in the Kenyan prison argot from a lexical pragmatic approach. This is because in the lexical pragmatic approach we analyze the meaning of words through context.

\section{Semantic Shift}

Semantic shift is a term used to refer to the evolution which a word usage undergoes resulting to a different meaning but often related to the original meaning. This process can also be referred to as semantic change, semantic drift or semantic progression. A semantic shift can, therefore, be referred to as the change in the meaning of a word.

There are different types of semantic changes [11]. He discusses narrowing, widening, hyperbole and metaphor among others. He explains that every semantic change of a word would affect other words in the lexical field. From Bloomfield's work, this article highlights some semantic changes that occur in the Kenyan prison lingo, out of which we find two major ones: lexical narrowing and lexical broadening. This study focuses on the two main types of semantic changes in which lexical broadening occurs in different ways.

Wambugu (2010) uses the lexical pragmatic approach to discuss the semantic shifts in in the Gikuyu language lexemes [12]. Much emphasis is put here on the different types of semantic shifts and ways in which other scholars have attempted to classify them. Wambugu relates much of her work from Wilson [13] and Muyuku [14]. This study is important because just as the Gikuyu language, Swahili is a Bantu language. The lexical pragmatic processes that affect the two languages are similar.
Atoh (2001) on the other hand carried out an analysis of the meaning of Dholuo Nouns, by using the semantic field approach [15]. His study was based on Nouns alone. This work provides a useful percolation to this study, particularly on Semantics. However, in the current work, we concentrate more on Noun phrases and Verb phrases.

Atichi (2004) investigated the divergences of the meaning of words in the Kenyan English [16]. He discusses the changes in the meaning of words and the factors that cause them. The meanings are discussed within the lexico-semantic dynamism. This work also provides a useful percolation to the current study particularly on narrowing and broadening. Mwebia (2006) on the other hand investigates sense relations in the Kimeru language basing his work on the lexical pragmatic theory [17].

Trier had asserted that every semantic change in a word would also affect other words in that lexical field [18]. This is corroborated by Ullmann $[19,20]$ who brings up an analysis beyond the single words. His study is borrowed from the word-field analyses of Trier [18]. Every time there is a semantic change in a word, certain changes must take place in terms of the final meaning of the word [20]. Sometimes the meaning could narrow down in that it becomes more specific compared to the earlier meaning. A semantic shift can also affect the meaning of the word by making it more general after broadening. Some lexemes change their meaning from positive to negative and vice versa.

Habwe (1999) explains that meaning goes beyond the normal and the usual linguistic properties in language [21]. In his work, he uses the pragmatic approach to analyze the Swahili Political Speeches. Blank [22] also writes about semantic changes. He discusses various forces that trigger semantic changes in language. Blank explains that the semantic changes could be caused by linguistic factors. Words could be used in different contexts to bring out different meanings that speakers wish to convey. He also discusses the psychological factors which may influence how people use words in a language depending on their perception of the words in the mind.

Having mentioned some vital research on semantic shift, it is important to highlight that there are other important works relevant to this study [23-26]. However, as they do not tackle the problem of prison argot, they will not be further discussed. We shall now discuss the types of semantic shift based on the Lexical Pragmatic Theory.

In Lexical pragmatics, two main types of lexical-pragmatic processes are distinguished, going by the ways in which the concept communicated in the use of a word differs from the concept encoded. These two processes according to Mmbwanga [27] are lexical narrowing and lexical broadening.

\subsection{Lexical Narrowing}

According to Bloomfield [11] lexical narrowing is the process through which the meaning of a word shifts from a super ordinate level to a subordinate level. The meaning of the word becomes less general or less inclusive than its 
original meaning. In other words, a word is used in a more specific sense than the encoded one. This results in the narrowing of the linguistically-specified denotation. Horn \& Ward (2004) explain lexical narrowing as a case where a word is used in a relatively more specific sense than the encoded one resulting in the narrowing of the linguisticallyspecified denotation [28]. The process increases implications and the hearer is entitled to narrow the interpretations until he has an interpretation that satisfies his expectation of relevance. For example, if we say all doctors drink, drink here might not convey the original sense 'drink liquid'; but more specifically drink alcohol or drink significant amounts of alcohol.

\subsection{Lexical Broadening}

According to Muyuku [14] in lexical broadening, a word is always used to convey a more general meaning than the encoded one leading to the widening of the linguisticallyspecified denotation. Campbell (1998) explains broadening as a process of widening of meaning which results from a generalization from the specific case to a class of which the specific case is a member [28]. He explains that a word starts out with an original meaning then it gets or acquires more multiple meaning. For example: Fly Emirates has bought a new big bird. The bird conveys more than the encoded sense. An assumption about the concept bird for example 'fly' that they fly is transferred to a set of flying things that relate to the Fly Emirates. Therefore the meaning of bird has been broadened to aeroplane. The lexical pragmatic theory highlights different varieties of lexical broadening, such as approximation, metaphoric extensions, category extensions and hyperbole, which will now be briefly discussed.

i Approximation

This is a type of broadening in which we use a word with a relatively strict sense to apply to a penumbra of cases which fall outside its linguistically-specified denotation. The defining feature of the encoded concept is dropped in the process of reaching the intended meaning. Carston (2004) explains that in this widening, a word with a strict sense is extended to a range of items which linguistically fall outside its denotation. For example, the bottle is empty [30]. Here the intended meaning is that the bottle is close enough to being empty but not empty as such.

\section{ii Category Extensions}

Category extension is identified by the use of salient brand names to refer to a broader category including items from less salient brands [31]. For example, Nissan is a brand name for a specific type of vehicle but the name is widely used to refer to all passenger service vehicles. Akmajian et. al. (2001) refer to category extension as broadenings in which the use of existing words become broader [32]. In the context of this study, therefore, the two terms are viewed to be synonymous. iii Metaphoric Extensions

A metaphoric extension is seen as a more radical widening which makes the communicated concept to depart much further from the original meaning. According to Trask [33] metaphor is a figure of speech which is based on the perceived similarity between distinct objects or actions. As figures of speech, metaphors are not taken literally. This extension involves a word with a concrete meaning taking on a more abstract sense, although the word's original meaning is not lost. For example, Maimuna is a flower. Maimuna falls very far outside the normal denotation of a flower. The context leads us to understand that Maimuna is either as beautiful as a flower or as fragile as a flower.

iv Hyperbole

Hyperbole is a radical type of broadening which allows the communicated concept to depart further from the encoded concept. For example, the water is boiling (hotter than expected or uncomfortably hot). This sentence would be an approximation if the water were almost boiling and a hyperbole if the water was merely hotter than expected, or uncomfortably hot.

\section{Method}

The contextual-dynamic method was used to collect data from the respondents. Slama-Cazacu (2004) explains that this method mainly concerns observation and dialogue [34]. Our interview was based on certain laid down guidelines to ensure that the respondents are subject to similar stimuli. We collected the data within one month. Each interview lasted for not more than 30 minutes. The respondents were assured that the study was being carried out for academic purposes only. The interviewer noted down the data in a book throughout the interview process.

\section{Population}

The study was carried out among the prisoners in Kibos and Kisumu maximum-security prisons in Kisumu County. Guided by the assumption that the proficiency of argot relates to an understanding and knowledge of prison life [35], the participants who were selected to this study had served at least three years in prison. We randomly sampled 40 male prisoners to be our respondents.

\section{Results and Discussion}

In lexical pragmatics, two main types of lexical-pragmatic processes are distinguished, corresponding to the ways in which the meaning communicated by use of a word differs from the meaning encoded. The two processes are lexical narrowing and lexical broadening [31]. We now turn to discussing lexical broadening in the Kenyan prison argot.

\subsection{Lexical Broadening}

As discussed earlier, this is the process in which the meaning of a word becomes more general than its semantic or historically earlier form [33]. Therefore a word conveys a more general meaning than the encoded one. In other words, what a word refers to increases. 
Table 1. Argot terms whose meanings have been broadened.

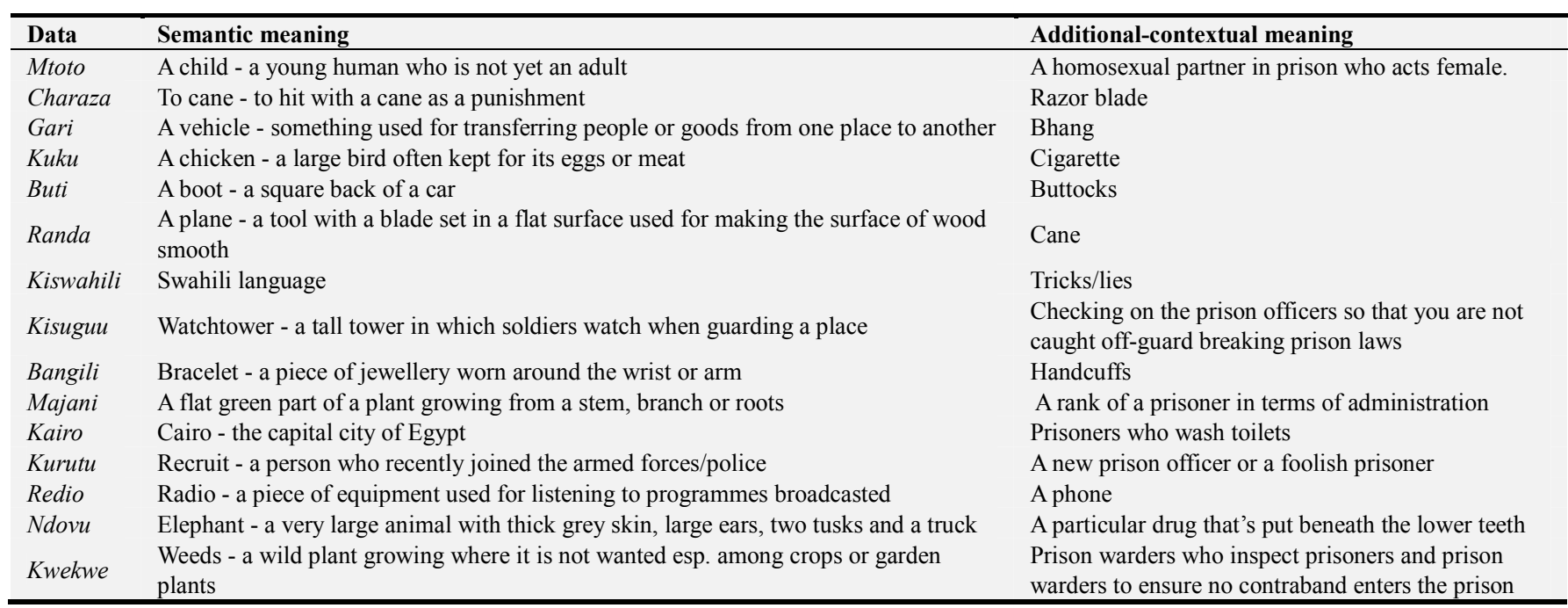

Table 1 shows argot terms that have gone through lexical broadening in the context of the Kenya prisons. In lexical broadening, the meaning of a word is expanded compared to the semantic meaning of the word. For example, semantically, the word mtoto in Swahili refers to a child; a young human who is not yet an adult [36]. However, in the prison context, the meaning of this word is expanded to mean a homosexual partner who acts female. The lexical meaning of the word Charaza in Swahili is to cane [36]. In prison, this word gets an additional meaning of a razor blade. Similarly, the word gari which semantically refers to a vehicle is expanded in meaning to also refer to bhang. The word gari acquires an additional meaning in the prison context.

The above lexemes acquire additional meanings though the original meanings are also used when the prisoners have no intentions of concealing information. We therefore agree with Ullman [37] who explains that the word acquires an additional meaning without losing its semantic meaning. Semantic expansion occurs in the Kenyan prison argot so as to help the prisoners to hide secrets.

Both metaphoric extension and hyperbole as types of lexical broadening are evident in the Kenyan prison argot. We shall now discuss these processes.

\subsubsection{Metaphoric Extension}

Table 2. Argot terms that have been expanded metaphorically.

\begin{tabular}{|c|c|c|}
\hline Data & Semantic meaning & Expanded meaning \\
\hline Mtoto & A child - a young human who is not yet an adult. & A homosexual partner in prison who acts female. \\
\hline Mwana & Son or a daughter of any age. & A homosexual partner in prison who acts female. \\
\hline Maua & Flower - a coloured part of a plant from which the seeds or fruits develop. & A homosexual partner in prison who acts female. \\
\hline Mende & $\begin{array}{l}\text { Cockroach - a large brown insect with wings that lives in houses especially } \\
\text { where there is dirt }\end{array}$ & A homosexual partner in prison who acts male \\
\hline Kijana & $\begin{array}{l}\text { Youth - the time of life when a person is young especially before a child } \\
\text { becomes an adult }\end{array}$ & A homosexual partner in prison who acts female. \\
\hline Malaya & Prostitute - a person who has sex for money & A prisoner who betrays the others to the prison authorities \\
\hline Kuku & A chicken - a large bird often kept for its eggs or meat & Cigarette \\
\hline Bata & $\begin{array}{l}\text { Duck - a common bird that lives on or near water with short legs. Bigger } \\
\text { than a chicken }\end{array}$ & Bhang \\
\hline Neti & $\begin{array}{l}\text { Net - a material made of string or wire twisted or tied together with small } \\
\text { spaces in between }\end{array}$ & Prison \\
\hline Roho & Soul - a spiritual part of a person believed to exist after death & $\begin{array}{l}\text { Prisoners who work in stores. They dress in white like } \\
\text { members of the Roho Church }\end{array}$ \\
\hline Malaika & $\begin{array}{l}\text { Angel - a spirit believed to be a servant of God and is sent by God to deliver } \\
\text { messages }\end{array}$ & Good and well-behaved prisoners \\
\hline Simba & $\begin{array}{l}\text { A Lion - a powerful animal of the cat family that hunts in groups and lives } \\
\text { in part of Africa and Southern Asia }\end{array}$ & An officer in charge of a prison \\
\hline Mtaro & A trench - a long deep hole dug in the ground & Buttocks \\
\hline Mzazi & A parent - a person's mother or father & The good and concerned prison officers \\
\hline Mwewe & A hawk - a strong fast bird of prey & $\begin{array}{l}\text { A glutton prisoner or prison officer who snatches the } \\
\text { prisoners' food for himself }\end{array}$ \\
\hline Nyoka & A snake - reptile with a long thin body and has no legs & A prisoner who betrays the others to the prison officers \\
\hline
\end{tabular}


Table 2 shows the argot terms that have undergone metaphoric expansion. A semantic change is taken to be metaphorical if one concept which is perceived by the speakers of the recipient language is similar to the new concept introduced from Source Language (SL) [38]. We agree with this statement because the above terms acquire figurative usage to refer to concepts perceived to be similar and acquired from the SL. The prisoners use words or expressions in the Swahili language figuratively so as to refer to various things and situations in their environment.

In table 2 above, the cognitive environment is used to extend the encoded concept maua on a homosexual male prisoner who acts female. The semantic meaning of maua in Swahili is a flower; a colored part of a plant from which the seeds or fruits develop. This prisoner is figuratively referred to as a flower because he has certain characteristics that are similar to that of a flower. For example, just as a flower, he has to be taken care of by his male partner. He is also perceived to be beautiful and fragile like a flower and just as the flower dries faster, most of the relationships in prison don't last for long. This homosexual partner in prison who acts female is also figuratively referred to as mwana, mtoto or kijana. Semantically, mtoto means a child, mwana means a son or a daughter of any age and Kijana is a youth. A child is fragile and needs care and attention. Similarly, the homosexual prisoner who acts female needs care, protection and attention from his partner. Because of this, this prisoner who acts female is referred to as a child, a youth or a son because of his demands for care. Prison is referred to as neti (a net) because of the way prisoners are confined within the prison walls and are unable to move out freely.

We agree with Aitchson [39] that a word can be broadened to refer to another word which comes from a different semantic field. A good example is the argot term $k u k u$, which in Swahili semantically refers to a chicken (a bird). This word is expanded in meaning to refer to a cigarette. The word chicken comes from the semantic field of birds whereas cigarette comes from the semantic field of drugs.

The above table confirms that a metaphorical change involves a word with a concrete meaning taking on a more abstract sense, although the word's original meaning is not lost.

\subsubsection{Hyperbole}

Different from metaphoric extension, hyperbole is a radical type of broadening that allows the communicated concept to depart further from the encoded concept. The Kenyan prison argot has the following hyperbolic extensions.

Table 3. Hyperbole.

\begin{tabular}{lll}
\hline Data & Semantic meaning & Contextual meaning \\
\hline Tero & Terrorism & Routine prison inspections by warders \\
Kunyeshewa randa & To be rained on by a smoothening plane & To be caned \\
Kuuza mtu & Selling someone for money & Reporting a fellow prisoner to be punished \\
Kukula copper & Eating copper & To be gunned down \\
Nchi ingine & Another world & Prison \\
Nchi ya saba & Seventh world & Prison \\
\hline
\end{tabular}

Table 3 shows the argot terms that have gone through hyperbolic expansion. Tero is a Sheng slang word borrowed from the English word terrorism. In prisons, there are routine inspections carried out in the prisoners' cells as well as on their bodies. Sometimes these inspections may involve physical confrontations between the prison wardens and the prisoners. Because the prisoners dislike these routine checkups they exaggerate the process and refer to it as tero, terrorism.

In the normal Swahili usage, kunyeshewa na randa means smoothening planes falling down on someone as rain does. This phrase is an exaggeration because it's not practically possible for smoothening plane to fall down in the manner that rain falls. In the prison context, kunyeshewa randa means being caned by the prison warders. Smoothening planes falling downs as rain is an exaggeration of caning.

When a prisoner reports a fellow prisoner to be punished by the prison warders, in the prison context, it is referred to as kuuza mtu. Kuиza mtu in the Swahili language literally means selling someone for money. The contextual meaning of kuuza mtu is further from the lexical meaning of the phrase in Swahili language. The pain of being betrayed by a fellow prisoner makes the prisoner to exaggerate the act of betrayal and refer to it as kuuza mtu, selling someone for money. To be gunned down, on the other hand, is exaggerated as eating copper (kukula copper).

Prison is exaggeratedly referred to as nchi ingine (another world), and nchi ya saba (seventh world). This is because the prisoners take the prison life to be very different from that in the free world. The prison life is full of pain, from overcrowding in the prison wards to harassments by prison wardens. Due to such pains and frustrations that prisoners undergo, they exaggeratedly refer to these correctional institutions as another world or seventh world (a world that is far away).

\subsection{Semantic Narrowing}

Fromkin \& Rodman (2003) explain semantic narrowing as words becoming more specialized in meaning [40]. Semantic narrowing is, therefore, the opposite of semantic broadening. The narrowed meaning makes the affected word to contain a meaning that differs from the SL meaning.

Table 4. Argot terms that have gone through semantic narrowing.

\begin{tabular}{lll}
\hline Data & Semantic meaning & Contextual-Narrowed Meaning \\
\hline Afande & Security officer/police & Prison officer \\
Kunyemelea & Approach stealthily & To violate sexually \\
\hline
\end{tabular}




\begin{tabular}{|c|c|c|}
\hline Data & Semantic meaning & Contextual-Narrowed Meaning \\
\hline$P a i$ & $\begin{array}{l}\text { Police officer - an official whose job is to make people obey the law and to solve and } \\
\text { prevent crime }\end{array}$ & Prison officer \\
\hline Kutia & To insert - to put something into something else or between two things & Engaging in sex \\
\hline Marufuku & Illegalities - acts or things declared illegal & Contrabands \\
\hline Mzigo & $\begin{array}{l}\text { Luggage - bags, cases etc. that contains someone's clothes and things when they are } \\
\text { travelling }\end{array}$ & Contrabands \\
\hline Unga & Flour & Cocaine \\
\hline Baraza & Council - a group of people who are elected to govern an area such as a city & A meeting of prisoners chaired by the head of a house \\
\hline Serikali & A particular system with the power of controlling a country & Prison administration or prison officer \\
\hline Kraoni & Security officer & Prison officer \\
\hline Kuonwa & To be recognized using eyes & To be visited in prison \\
\hline Wadhii & People - Men, women, and children & Prisoners \\
\hline
\end{tabular}

From the above table, the argot terms afande and kraoni derived from the Swahili language, and pai, derived from the Sheng slang can be used to refer to any security officer in the disciplined forces. However, in the prison context, the meanings of these terms are restricted to a particular type of a security officer in the disciplined forces, that is, the prison officers.

The examples confirm that in lexical narrowing, a term or word is used in a more specific sense than the encoded one, resulting in narrowing of the linguistically-specified denotation [41].

Semantically, kunyemelea means to approach stealthily [36]. There are many reasons why somebody can approach someone stealthily. You can approach stealthily to robe, to kill, to see, to arrest or for any other purpose. In the prison context, the meaning of kunyemelea is restricted to approaching stealthily with the intention of violating someone sexually.

Kutia semantically means to insert; to put something into something else or between two things [36]. Many things can be inserted. You can insert clothes in a bag or insert your hands in the pocket. However, in the prison context, kutia (insertion) is very specific, inserting the male organ into another prisoner's bottom. The meaning is restricted.

The lexical meaning of marufuku in Swahili is illegalities. These are acts or things declared illegal [36]. This meaning is more general and inclusive. In the prison context, a listener has to restrict the meaning of the word so as to reach the intended meaning. Among the prisoners, marufuku only refers to the items which have been declared illegal by the prison administration or authorities. This meaning is more specific and restricted compared to the lexical meaning of the term. Marufuku in the prison refers to contraband.

In standard Swahili, mzigo means luggage, something heavy which has been carried by someone [36]. This meaning is more inclusive. Mzigo could be bags, cases, books or stones. In the Kenyan prison context, when a prisoner speaks about mzigo, the meaning is restricted to contraband, drugs which are ferried in the prison illegally.

Unga literally means flour or something which has been crushed and ground to be powdery [42]. In the common usage of the word, this meaning is wide. Unga could be unga wa mahindi (maize flour), unga wa mtama (wheat flour) etc. In the prison discourse, unga is not any other powdery thing but cocaine. This meaning is restricted to a particular type of a drug. Similarly, baraza, a Swahili word which means a council; a group of people who are elected to govern an area such as a city [36], is restricted to only mean a meeting of prisoners chaired by the house in charge.

The dictionary meaning of Serikali in Swahili is government, a particular system with the power of controlling a country [36]. There are different arms of government, the legislature, the judiciary and the executive. In the prison discourse, the meaning of the word government is restricted to mean the prison administration.

Wadhii is an argot term borrowed from the Sheng slang used among the youths in Kenya. The word originates from the Swahili word, watu which means people. This meaning is wide and more inclusive. It involves any person; prisoners, warders, teachers, thieves, students etc. However, in the prison context, the prisoners use the word in a restricted sense. It only means prisoners and not any other group of people.

\section{Conclusion}

This paper concerned itself with the analysis of the semantic changes in the Kenyan prison argot. The discussion shows how the standard Swahili words, some Standard English words, and some streets slang words undergo radical semantic change in the prison context. The words are demonstrated to have acquired new meanings resulting to specialization or generalization of their semantic sphere. Semantic change has been observed to be an important component of the Kenyan prison argot. From the discussions it can be concluded that the primary reason why prisoners change the meaning of words is to conceal information.

This study shows that context is quite instrumental for the interpretation of the meaning of a word which has undergone a semantic change in prison. In this regard, the lexical pragmatic approach is suitable in analyzing the changes in meaning in the prison argot. It can also be concluded that the Kenyan prison argot is highly creative and rich in meaning. This is manifested through the use of metaphors, hyperbole, and narrowing of the meaning of words.

\section{References}

[1] Dziedzic-Rawska, A. (2016). "Linguistic Creativity in American Prison Settings". Lublin Studies In Modern Languges and Literature 40 (1). 
[2] Ciechanowska, A. (2016). Some Remarks on a Linguistic Predator: Foreign Influences upon Prison Slang.

[3] Keith, G., \& Shuttleworth, J. (2000). Living Language. London: Hodder and Stoughton.

[4] Nyota, S. \& Mareva R. (2012). "What's New in Shona Street Lingo? Semantic Change in Lingo. Adoptive from Mainstream Shona. International Journal of English Linguistics; 2.

[5] Louwrens, L. J. et al. (1992). Only Study Guide for SEMANO$T$ (revised ed.). Pretoria: UNISA.

[6] Binyanya, M. (2014). Sajili ya Maafisa wa Polisi: Tathmini ya Matumizi ya Lugha ya Kiswahili katika Kituo cha Polisi cha Central, Nairobi. Unpublished MA thesis, UoN.

[7] Mugendi, N. (2016). Morphology of the Gitamanya argot of the Matatu Crew of Embu Town; Unpublished MA Thesis: Kenyatta University.

[8] Nyakundi, P. (2010). Motivation, Morpho-phonological Processes in Egesemba Argot Among Ekegusii-Speaking Males of Western Kenya; Unpublished MA Thesis: Kenyatta University.

[9] Ogutu P., Opande N. \& Oluoch S. (2018). "Kiswahili ya Jela: The Features of the Kenyan Prison Argot." International Journal of Language and Linguistics. Vol. 6, No. 6, pp. 185196.

[10] Ciechanowska, A. \& Kleparski, G. (2015). On the Semantic Features of Prison Slang. Token: A Journal of English Linguistics.

[11] Bloomfield, L. (1933). Language. London: Compton Printing Ltd.

[12] Wambugu, W. (2010). Semantic Shifts in Gikuyu Lexemes: A Lexical Pragmatic Approach. Unpublished M. A. Thesis: University of Nairobi.

[13] Wilson, D. (2006/2007). Issues in Pragmatics, (PLIN 3001).

[14] Muyuku, A. (2009). Language Mixing in the Language of Advertising: A Case Study of Commercial Banks and Mobile Telecommunications in Kenya, Unpublished M. A. Thesis: University of Nairobi.

[15] Atoh, F. (2001). Semantic Analysis of Dholuo Nouns: The semantic field Approach. Unpublished MA thesis, UoN.

[16] Atichi, R. (2004). The Semantic Distinctiveness of Kenyan English. Unpublished MA thesis, UoN.

[17] Mwebia, F. (2006). A Lexical Pragmatic Analysis of the Sense Relations in Kimeru. Unpublished M. A Dissertation, UoN.

[18] Trier, J. (1931). Der deutsche Wortschatz im Sinnbezirk des Verstandes. Heidelberg: Winter.

[19] Ullmann, S. (1957). The Principles of Semantics, Blackwell, and Mott.

[20] Ullmann, S. (1962). An Introduction to the Science of Meaning, Oxford: Blackwell.

[21] Habwe, J. (1999). A Discourse Analysis of Swahili Political
Discourse. Unpublished Ph. D. Thesis. Nairobi: University of Nairobi.

[22] Blank, A. (1998). Historical Semantics and Cognition, Berlin and New York: Mouton.

[23] Lyons, J. (1977). Semantics. vol. 1. Cambridge. Cambridge University Press.

[24] Yule, G. (1996). The Study of Language. United Kingdom: Cambridge University Press.

[25] Hurford, J. \& Heasley, B. (1983). Semantics: A Coursebook. Cambridge: Cambridge University Press.

[26] Murphy, L. (2003). Semantic Relations and the Lexicon, Cambridge: C. U. P.

[27] Mmbwanga, K. (2010). New Words and Meanings on Facebook: A Lexical Pragmatics Analysis, Unpublished M. A. Thesis: University of Nairobi.

[28] Horn, L. \& Ward, G. (eds) (2004). The Handbook of Pragmatics. Oxford: Blackwell.

[29] Campbell, L. (1998). Historical Linguistics: An Introduction. Edinburg University Press.

[30] Carston, R. (2004). Thoughts and Utterances: The Pragmatics of Explicit Communication. Oxford: Blackwell Publishers Limited.

[31] Wilson, D. (2003). Relevance and Lexical Pragmatics, in Italian Journal of Linguistics, Italy.

[32] Akmajian et al. (2001). An Introduction to Language and Communication, U. S. A: M. I. T.

[33] Trask, K. (1994). Language Change, Routledge.

[34] Slama-Cazacu, T. (2000). Stratageme comunicaţionale şi manipularea-Iasi Polirom.

[35] O'Donnell, I. (2004). Prison rape in context. The British Journal of Criminology, 44 (2), 241-255.

[36] TUKI (2013). Kamusi ya Kiswahili Sanifu. Oxford University Press.

[37] Ullmann, S. (1970). Semantics: An Introduction to the Science of Meaning. Oxford: Basil.

[38] Anttila, R. (1989). Historical and Comparative Linguistics. Amsterdam: John Benjamins.

[39] Aitchison, J. (2003). Words in the Mind: An Introduction to the Mental Lexicon. (Third Edition). U. S. A: Blackwell Publishing Limited.

[40] Fromkin, V. \& Rodman, R. (2003). An Introduction to Language. Massachusetts: Heinle.

[41] Wilson, D. (2006/2007). Issues in Pragmatics, (PLIN 3001).

[42] Mdee, J., Njogu, K. \& Shafi A. (2011) Kamusi ya Karne ya 21, Nairobi; Longhorn Publishers Limited.

[43] Ullman, S. (1977). “Change of Meaning”. In H. Hungerford et al., English Linguistics. Illinois: Scott, Foresman, and Company. 